\title{
Cycloheximide promotes paraptosis induced by inhibition of cyclophilins in glioblastoma multiforme
}

\author{
Lin Wang ${ }^{1}$, Justin H Gundelach ${ }^{3}$ and Richard J Bram ${ }^{\star, 2,3}$
}

Cancer is the second leading cause of death worldwide. Current treatment strategies based on multi-agent chemotherapy and/or radiation regimens have improved overall survival in some cases. However, resistance to apoptosis often develops in cancer cells, and its occurrence is thought to contribute to treatment failure. Non-apoptotic cell death mechanisms have become of great interest, therefore, in hopes that they would bypass tumor cell resistance. Glioblastoma multiforme (GBM), a grade IV astrocytic tumor is the most frequent brain tumor in adults, and has a high rate of mortality. We report that NIM811, a small molecule cyclophilin-binding inhibitor, induces catastrophic vacuolization and cell death in GBM cells. These unique features are distinct from many known cell death pathways, and are associated with an incompletely defined cell death mechanism known as paraptosis. We found that NIM811-induced paraptosis is due to unresolved ER stress. The abnormal upregulation of protein translation was responsible for the build-up of misfolded or unfolded proteins in ER, whereas pro-survival autophagy and UPR signals were shutdown during prolonged treatment with NIM811. Although cycloheximide has been claimed to suppress paraptosis, instead we find that it only temporarily delayed vacuole formation, but actually enhanced paraptotic cell death in the long term. On the other hand, mTOR inhibitors rescued cells from NIM811-induced paraptosis by sustaining autophagy and the UPR, while specifically restraining cap-dependent translation. These findings not only provide new insights into the mechanisms underlying paraptosis, but also shed light on a potential approach to enhance GBM treatment.

Cell Death and Disease (2017) 8, e2807; doi:10.1038/cddis.2017.217; published online 18 May 2017

Glioblastoma multiforme (GBM) is the most malignant brain tumor and is essentially always associated with a poor prognosis. ${ }^{1}$ Common treatments, including surgical resection, radiation or chemotherapy, are primarily given without the expectation of permanent cure, and can only offer patients a median survival rate of about 1 year. $^{2}$ Therefore, it is crucial to develop novel therapies that could improve survival.

GBM cells frequently develop genetic alterations that help them escape the apoptotic programmed cell death pathway. ${ }^{3}$ Hence, discovery and utilization of new cell death mechanisms could lead to improved GBM treatments. Paraptosis, an atypical cell death pathway, was first described in $2000 .{ }^{4}$ It has loosely been characterized by morphologic criteria (including ballooning cytoplasmic vacuolization and retention of normal nuclear architecture) and non-involvement of the caspases. ${ }^{5}$ Inhibition by the protein synthesis inhibitor cycloheximide has also been a key feature. ${ }^{5-7}$

Cyclophilins have long been known as foldases and protein chaperones. ${ }^{8}$ Recently, cyclophilins have been found to be overexpressed in many different types of cancers, and have been thought to support malignant transformation, ${ }^{9}$ by enhancing survival of cancer cells. Small molecule inhibitors of the cyclophilins may therefore be useful as anticancer agents. Although cyclosporine A has a high binding affinity to the majority of cyclophilins, ${ }^{10}$ it is not a suitable drug for the treatment of cancer because of its toxic effects on the kidneys and the immune system. ${ }^{11}$ Specifically, the cyclosporine
A-cyclophilin complex leads to inhibition of calcineurin, a serine/threonine protein phosphatase that is required for NF-AT-mediated T-cell activation. ${ }^{12}$ We have instead explored the potential of using NIM811 (Melle4-cyclosporine), which is a cyclosporine derivative that does not interfere with T-cell activation because it lacks affinity for calcineurin, ${ }^{13}$ and has higher binding affinity for the peptidyl-prolyl isomerase (PPlase) domain of cyclophilins. ${ }^{14}$

Here we used NIM811 to induce death in GBM cells, and found that its primary mode of action is to induce paraptosis. By deciphering the cellular events that take place after NIM811 treatment, we have obtained an in-depth understanding of the cell transition points from life to death during this process. We were also able to identify the critical pathways required for GBM cell survival. Importantly, we found that cycloheximide could only provide a brief inhibition of vacuolization but unexpectedly facilitated cell death in the long run. Our findings indicate that NIM811 activates paraptosis through promoting protein translation and simultaneously hindering the UPR response and autophagy activity, which together lead to irreversible disruption of the ER and cell death.

\section{Results}

NIM811-induced paraptosis-like cell death in GBM cells. Based on the observations that cyclophilins are upregulated in many types of cancers, ${ }^{15}$ especially in brain tumors, ${ }^{16}$ we

\footnotetext{
${ }^{1}$ Department of Biochemistry and Molecular Biology, Mayo Clinic, Rochester, MN, USA; ${ }^{2}$ Department of Immunology, Mayo Clinic, Rochester, MN, USA and ${ }^{3}$ Department of Pediatric and Adolescent Medicine, Mayo Clinic, Rochester, MN, USA

${ }^{*}$ Corresponding author: R J Bram, Department of Pediatric and Adolescent Medicine, Mayo Clinic, 200 First Street SW, Rochester, MN 55905, USA; Tel: +1 507266 0378; Fax: +1 507284 3757; E-mail: richard.bram @mayo.edu

Received 04.11.16; revised 22.3.17; accepted 05.4.17; Edited by Y Shi
} 
tested the ability of NIM811 to kill several human GBM cell lines. Treating the cell lines, U251 and T98G, with NIM811 indeed caused substantial degrees of cell death when used at $10-15 \mu \mathrm{M}$ concentrations after approximately $24 \mathrm{~h}$ (Supplementary Figures $1 \mathrm{~A}$ and $1 \mathrm{~B}$ ). Unexpectedly, rather than the typical morphological changes characteristic of apoptosis, we found that NIM811 induced the formation of massive vacuoles inside of the cells before death (Supplementary Figures 1B and 13). Unlike etoposide or staurosporine-initiated apoptosis, NIM811-treated cells did not go through an early stage in which they would stain for Annexin- $V$ by virtue of phosphatidyl-serine exposure and negative for propidium iodide $(\mathrm{PI}) .^{17,18}$ Instead, NIM811treated cells transitioned directly from PI-, Annexin-V double-negative to double-positive stained dead cells (Supplementary Figures $1 \mathrm{C}$ and 11). Furthermore, addition of the pan-caspase inhibitor Qvd-oph ${ }^{19}$ did not rescue death elicited by NIM811, although did rescue etoposide or staurosporine-induced apoptosis (Figure 1a and Supplementary Figure 10). Knocking down of Apaf1 or MLKL was also incapable of blocking NIM811-induced death (Supplementary Figure 12). The necroptosis inhibitor Necrostatin-1 (ref. 20) was effective at suppressing shikonin-stimulated ${ }^{21}$ killing, but was unable to save NIM811-treated cells (data not shown). Electron microscopic examination revealed the inside structure of NIM811-treated U251 cells, in which large single membrane-bound vacuoles surrounded the intact nuclei (Figure 1b). Together, these observations suggested that NIM811 may induce death via paraptosis. ${ }^{5}$
Previous reports have indicated that paraptotic death is accompanied by formation of vacuoles that arise from either the ER or the mitochondria. ${ }^{6,7}$ To identify the source of vacuoles in NIM811-treated cells, we transfected them with an expression construct that fuses GFP with the ER signal sequence and KDEL ER retention domain of calreticulin to enable long-term labeling of ER. After $20 \mathrm{~h}$ of NIM811 treatment, the vacuoles colocalized precisely with the ER-GFP fluorescence. However, co-transfecting with mitochondria or lysosome labeling constructs showed no colocalization, indicating that the vacuoles were exclusively generated from ER (Figure 1c).

NIM811 delays tumor growth in mice. To determine whether tumor cells may also be subject to NIM811induced death in vivo, we conducted a study using a xenograft model of human GBM. We first verified that human GBM G22VF cells from the Mayo Brain Tumor SPORE core facility behaved similarly to U251 and T98G cells. NIM811 at $15 \mu \mathrm{M}$ stimulated similar vacuolization of G22VF cells by $24 \mathrm{~h}$ and significant cell death at $48 \mathrm{~h}$ (Figure 2a). G22VF cells were then subcutaneously inoculated into nude mice $(n=30)$. When tumor size reached $100 \mathrm{~mm}^{3}$, mice were randomly divided into three groups to receive three times per week of drug treatments: group one received vehicle treatment; group two mice received $25 \mathrm{mg} / \mathrm{kg}$ of NIM811 by intraperitoneal injection (IP); group three mice received $25 \mathrm{mg} / \mathrm{kg}$ of NIM811 via oral gavage. Although not curative on its own at this dosing schedule, we observed that both cohorts of

a
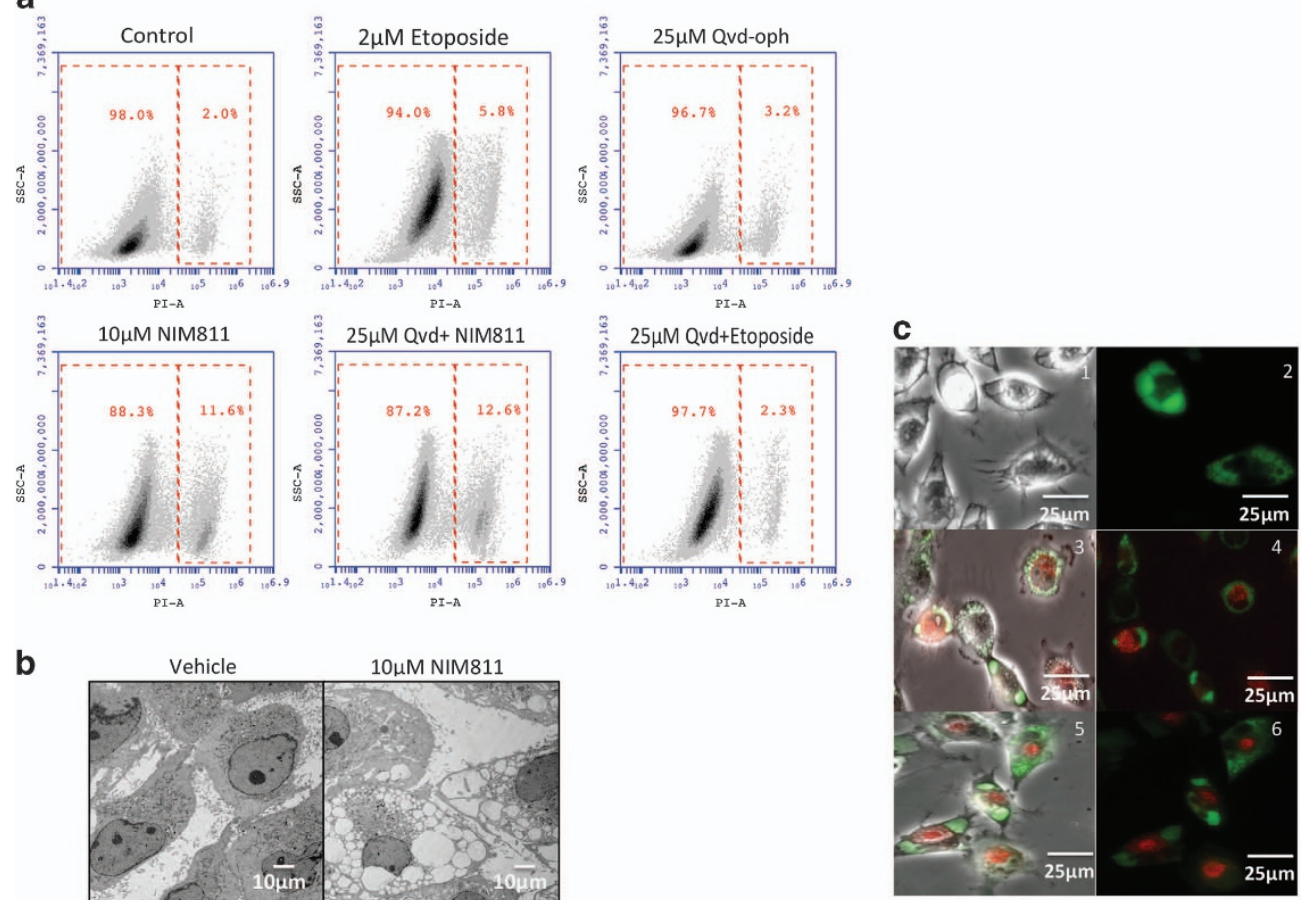

Figure 1 NIM811 induces ER vacuolization and paraptosis cell death in GBM cells. (a) Pan-caspase inhibitor Qvd-oph was not able to rescue cell death induced by $10 \mu \mathrm{M}$ NIM811 at $24 \mathrm{~h}$. (b) Electron microscopic images revealing the morphological structures of vacuoles, scale bar $=10 \mu \mathrm{m}$. (c) Labeling cells with GFP-ER signal sequence of calreticulin-KDEL (1-2) and TagRFP-Leader sequence of E1 alpha pyruvate dehydrogenase (3-4) or RFP-lamp1 (5-6) indicate that the vacuoles originate from the ER. Scale bar $=25 \mu \mathrm{m}$ 

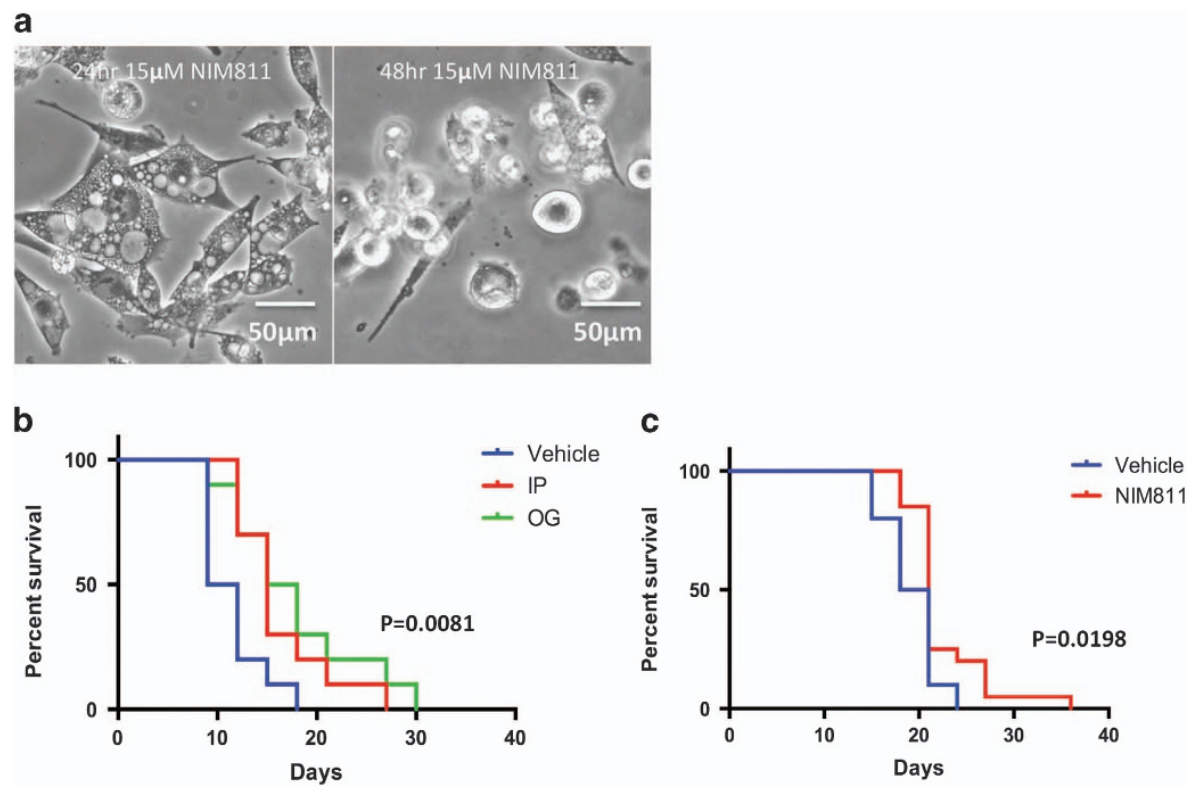

Figure 2 NIM811 inhibits tumor growth in vivo (a) $15 \mu \mathrm{M}$ of NIM811 caused vacuolization in G22VF cells at $24 \mathrm{~h}$, and substantial cell death at $48 \mathrm{~h}$. Scale bar $=50 \mu \mathrm{m}$. (b) Nude mice $(n=30)$ were injected subcutaneously with $2 \mathrm{E}^{6} \mathrm{G} 22 \mathrm{VF}$ cells. When the mice developed tumors larger than $100 \mathrm{~mm}^{3}$, they were randomly divided into three groups to receive treatments: vehicle (1\% ethanol+9\% cremophor EL+ 90\% normal saline), NIM811 intraperitoneal ( $25 \mathrm{mg} / \mathrm{kg})$, NIM811 oral gavage (25 mg/kg). Using $1 \mathrm{~cm}{ }^{3}$ as cut-off, NIM811-treated mice had slower tumor growth rate than the mice in vehicle group. Curves were significant different by the log-rank (Mantel-Cox) test, $P=0.0081$. (c) Using tumor size of $2.5 \mathrm{~cm}^{3}$ as killing criteria, NIM811-treated mice survived longer than vehicle-treated mice. Curves were significantly different by log-rank (Mantel-Cox) test, $P=0.0198$

NIM811-treated mice reached the interim analysis threshold size $\left(1 \mathrm{~cm}^{3}\right)$ and mandatory killing size $\left(2.5 \mathrm{~cm}^{3}\right)$ significantly later than vehicle only treated mice (Figures $2 b$ and $c$ ). We conclude that NIM811 has activity against GBM cells in vitro and in vivo.

NIM811-induced vacuolization depends upon protein synthesis but does not require loss of proteasome activity. Although NIM811 treatment typically took at least $20 \mathrm{~h}$ to cause vacuolization and cell death, we found that these effects were irreversibly initiated by as little as $9 \mathrm{~h}$ of exposure to the compound (Figure 3a). Previous studies on paraptosis have suggested that vacuolization and death may depend upon ongoing protein synthesis and inhibition of proteasomal activity, thus leading to ER stress. ${ }^{5-7}$ To determine the impact of NIM811 on these functions, we first explored the role of protein synthesis using inhibitors. As was shown in the case of other paraptotic inducers, cells exposed to cycloheximide for only $2 \mathrm{~h}$ before treatment with NIM811 did not develop cytoplasmic vacuoles, indicating that the brief interruption of protein synthesis prevented the formation of enlarged ER structures $48 \mathrm{~h}$ later. We also tested blasticidin, a completely different protein synthesis inhibitor, ${ }^{22}$ and found that it also was able to prevent NIM811-induced vacuolization (Figure 3b). Unlike some inducers of paraptosis, the effects of NIM811 did not require MEK activation, ${ }^{5,7,23}$ as U0126 did not block vacuolization (Figure 3b).

Paraptosis has been associated with accumulation of misfolded or unfolded proteins, ${ }^{23}$ so we examined total proteins in NIM811-treated cells for ubiquitination, which targets polypeptides for proteasome-mediated degradation. ${ }^{24}$ Indeed, overnight incubation of NIM811 greatly augmented the amount of ubiquitinated proteins, an effect that was alleviated by cycloheximide pretreatment (Figure 3c). Accumulation of ubiquitinated proteins could indicate that NIM811 suppresses proteasomal activity. However, NIM811-treated cells had almost normal activity of proteasomes even after prolonged treatment (Figure 3d).

NIM811 elicited early activation of ER stress, autophagy and mTOR signaling. In order to identify potential mechanisms underlying NIM811-associated cell death, we performed RNA-seq to compare gene expression profiles between NIM811-treated cells and cells treated with vehicle. As anticipated from the marked impact of NIM811 on ER morphology, we found upregulation of multiple ER stress response genes, including HSPA5, ATF3, ATF4 and CHOP (Supplementary Table 1). Based on western blotting, ATF4 and P-elF2a increased transiently during early exposure to NIM811 (Figure 4a). BIP was induced to higher levels, which were maintained for $48 \mathrm{~h}$, together consistent with prolonged ER stress (Figures $4 \mathrm{~b}$ and $7 \mathrm{~d}$ ) and with transient activation of the UPR.

Unexpectedly, the gene encoding ATG8 was significantly elevated, and several other genes related to autophagy including LC3B, p62, ULK1 were also upregulated in NIM811-treated cells (Supplementary Table 1). Induction of autophagy in NIM811-treated cells was verified by transfecting U251 cells with GFP-tagged LC3B. ${ }^{25}$ We observed the formation of LC3-positive puncta starting shortly after addition of drug, and becoming more extensive by 3-6 $\mathrm{h}$ of exposure to NIM811 incubation, long before the appearance of cytosolic vacuoles (Figure 4c). Western blotting for LC3-I to II conversion and p62 degradation also verified activation of 


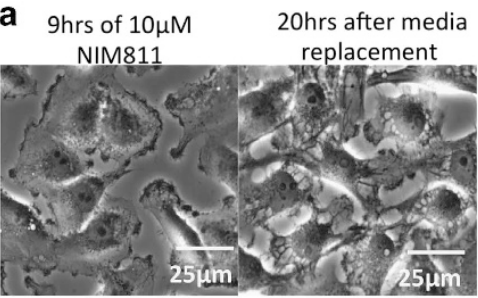

b NIM811 only $2 \mathrm{hrCHX}+\mathrm{NIM} 8112 \mathrm{hr}$ Blasticidin + NIM811 $2 \mathrm{hr}$ U0126 + NIM811

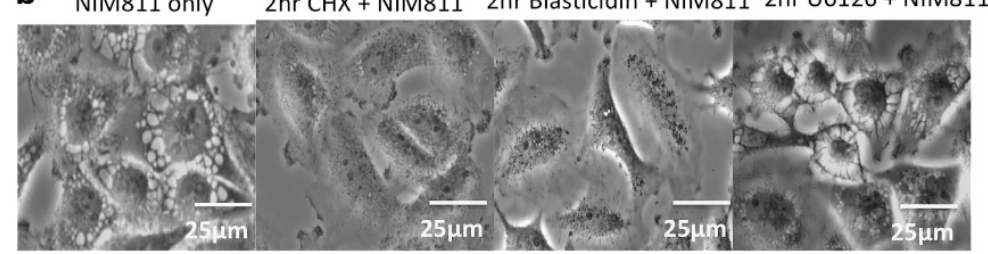

d

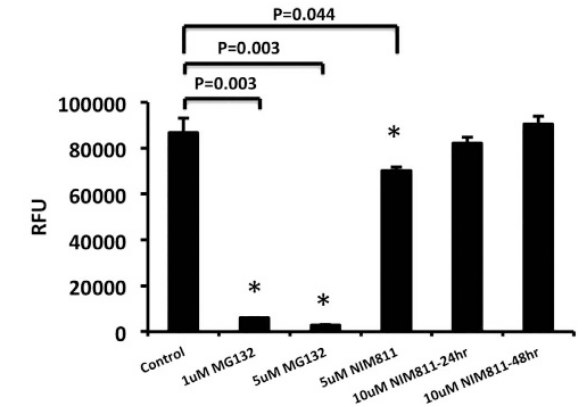

Figure 3 NIM811-induced vacuolization is sensitive to protein synthesis inhibition. (a) U251 cells were incubated with $10 \mu \mathrm{M}$ NIM811 containing media for $9 \mathrm{~h}$, then media were replaced with fresh DMEM (10\% FBS). Cells were then tracked by live microscopy (scale bar $=25 \mu \mathrm{m}$ ) for $24 \mathrm{~h}$. (b) U251 cells were pretreated with $20 \mu \mathrm{M}$ cycloheximide $(\mathrm{CHX})$ or $10 \mu \mathrm{g} / \mathrm{ml}$ of blasticidin or $20 \mu \mathrm{M}$ of U0126 respectively for $2 \mathrm{~h}$ followed by $24 \mathrm{~h} 10 \mu \mathrm{M}$ NIM811 incubation (scale bar $=25 \mu \mathrm{m}$ ). (c) Twenty hours of NIM811 treatment leads to accumulation of ubiquitinated proteins, pretreatment with $20 \mu \mathrm{M}$ cycloheximide for $2 \mathrm{~h}$ prevented this build-up. (d) After $24 \mathrm{~h}$ or $48 \mathrm{~h}$ of $10 \mu \mathrm{M} \mathrm{NIM} 811$ treatment, cells were collected for 20S proteasome activity assay. Cells treated with 1 or $5 \mu \mathrm{M} \mathrm{MG132} \mathrm{served} \mathrm{as} \mathrm{positive} \mathrm{control} \mathrm{for} \mathrm{this} \mathrm{assay}$

autophagy at approximately 4-6 h of treatment (Figure $4 \mathrm{~d}$ ). However, by $24 \mathrm{~h}$, p62 protein loss was reversed, and it began to accumulate, regardless of continued LC3-I to -II conversion (Figures $4 \mathrm{e}-\mathrm{g}$ ) suggesting that autophagy activity may be impaired after prolonged NIM811 treatment.

Increased rates of autophagy may be an effect of NIM811 by which it induced death, or may arise in response to cellular stress, to resist death. To determine the relationship between autophagy and cell death, we combined NIM811 with the autophagy inhibitors chloroquine ${ }^{26}$ or bafilomycin- $\mathrm{A} 1^{27}$ then monitored vacuole formation and survival. Chloroquine and bafilomycin A1 accelerated NIM811-induced vacuolization and death (Figures $5 \mathrm{a}$ and $\mathrm{b}$ ), and suppressed Bip expression (Supplementary Figures $8 \mathrm{~A}$ and $8 \mathrm{~B}$ ), suggesting that autophagy may be a survival response in these cells. In addition, shRNA-mediated knockdown of Beclin-1 or ATG5 made U251 cells more sensitive to NIM811-induced paraptotic effects (Supplementary Figures $8 \mathrm{C}$ and $8 \mathrm{E}$ ). Conversely, pretreatment of cells with the mTOR inhibitors rapamycin ${ }^{28}$ or torin- $2^{29}$ to activate autophagy significantly decreased vacuolization (Figure 5c), further supporting the idea that the induction of autophagy in response to NIM811 resists or delays the ultimate cellular demise.

Given the significant effect of the mTOR inhibitors, we examined its state in NIM811-treated cells. Importantly, we observed a substantial activation of both $\mathrm{mTOR}$ and its potential upstream activator AKT, as evidenced by the appearance of phospho-mTOR and phospho-AKT, which peaked between 2 and $6 \mathrm{~h}$ after addition of NIM811 (Figures $5 \mathrm{~d}$ and e). This activation preceded the accumulation of unfolded ubiquitinated proteins that began $10 \mathrm{~h}$ from NIM811 addition (Figure 5f). A 4-h pretreatment with either mTOR inhibitor diminished the accumulation of ubiquitinated proteins in NIM811-treated cells (Supplementary Figure 2A), and converted the upregulation of $\mathrm{P}$-elF2a from a transient to a sustained course, lasting over $48 \mathrm{~h}$ (Supplementary Figure 2B).

NIM811 stimulates both Cap-independent (CI) and Cap-dependent (CD) translation. Together, these data implicated cell vacuolization and death as arising from uncontrolled delivery of proteins into the ER in the face of impaired or insufficient handling of these misfolded proteins, perhaps because of failure to fully activate autophagy and failure to sustain activation of the UPR. In this case, suppressing protein synthesis by cycloheximide or blasticidin blocked the development of ER-derived vacuoles. On the other hand, mTOR inhibition suppressed vacuole formation most likely through increasing autophagy and extending the time course of the UPR. However, mTOR itself is known to regulate several components involved in protein synthesis. ${ }^{30}$ 


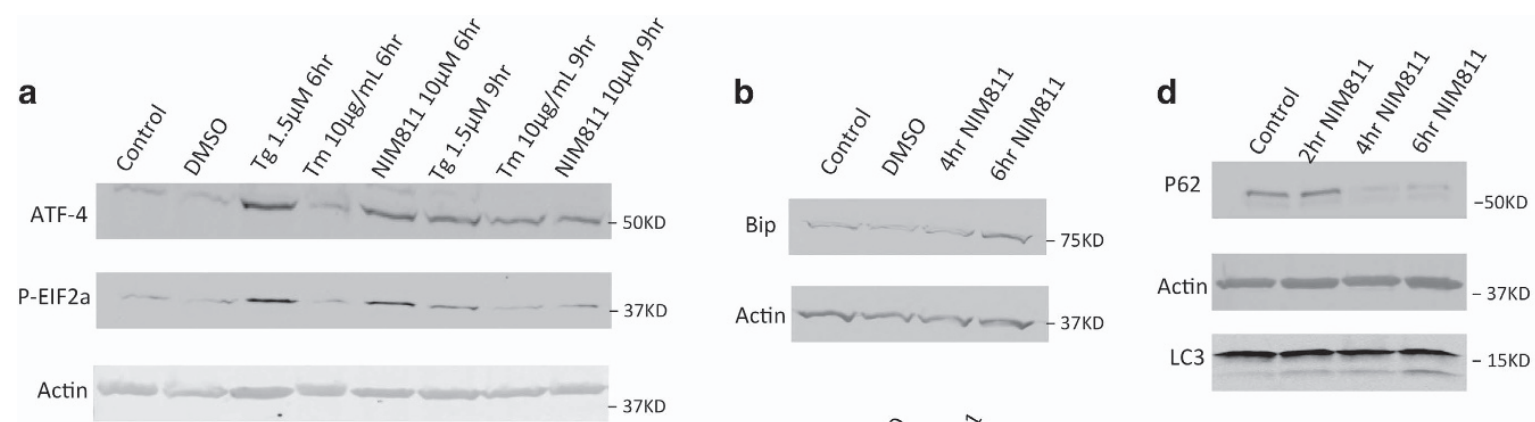

c
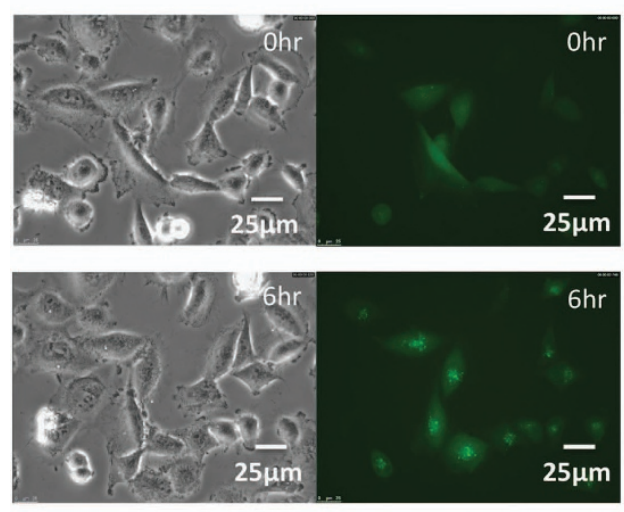
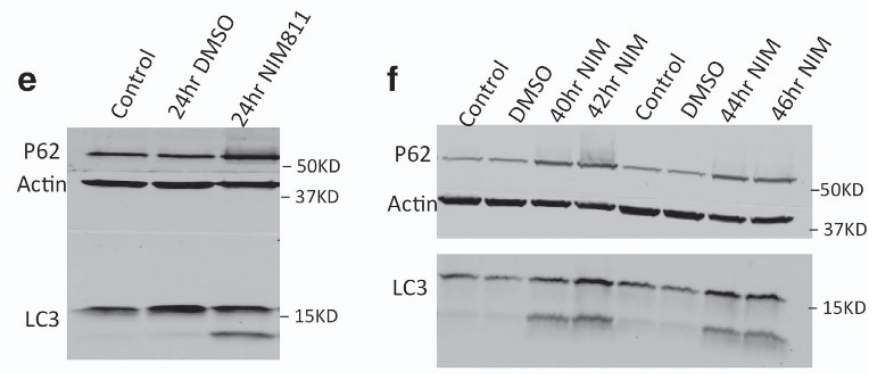

g

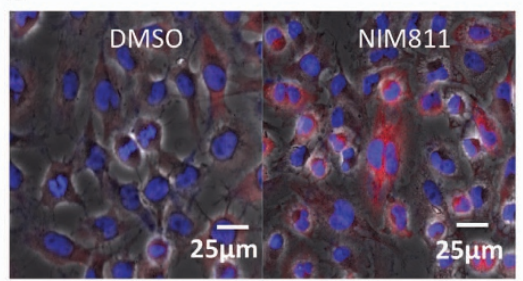

Figure 4 NIM811 induced a transient upregulation of UPR and autophagy. (a and $\mathbf{b}$ ) In all, $0 \mu \mathrm{M}$ NIM811 transiently induced UPR signaling (P-EIF2a, Bip, ATF4, CHOP upregulation) at $6 \mathrm{~h}$, but except for Bip, the activation of UPR mediators disappeared at $9 \mathrm{~h}$. Tunicamycin (Tm) and thapsigargin (Tg) were used as positive controls for the UPR. (c) In total, $10 \mu \mathrm{M}$ NIM811 was added to GFP-LC3B transfected U251 cells and imaged by fluorescence microscopy at $0 \mathrm{~h}$ and $6 \mathrm{~h}$. Scale bar $=25 \mu \mathrm{m}$. LC3 puncta were detected at 3-6 h. LC3 puncta formation occurred before the appearance of vacuoles. (d) LC3-I and -II conversion occurred at 4-6 h of $10 \mu \mathrm{M} \mathrm{NIM811} \mathrm{treatment} \mathrm{accompanied} \mathrm{by}$ p62 degradation. (e and f) In all, $10 \mu \mathrm{M}$ NIM811 incubation caused p62 accumulation at $24 \mathrm{~h}$, which persisted at later time points (40-46 h). (g) Immunofluorescence staining of SQSTM1/p62 (red) and nucleus (blue) after $24 \mathrm{~h}$ vehicle (left) or $10 \mu \mathrm{M}$ NIM811-treated (right) U251 cells. Scale bar $=25 \mu \mathrm{m}$

Two types of protein translation systems exist in cells, having opposing roles in ER stress. ${ }^{31-33}$ Typically, under conditions of ER stress, the UPR activates PERK, which phosphorylates elF2a. ${ }^{34} \mathrm{P}$-elF2a specifically downregulates $\mathrm{CD}$ translation but spares $\mathrm{Cl}$ translation to alleviate the overall protein burden in the ER and increase the synthesis of ER chaperones, respectively. ${ }^{35-37}$ This allows the ER increased time and capacity to process incoming proteins. We transfected cells with a bicistronic luciferase plasmid ${ }^{38}$ to help differentiate $\mathrm{CD}$ translation from $\mathrm{Cl}$ translation under the influence of various concentrations of NIM811 at 24 and $48 \mathrm{~h}$ of incubation. Both $\mathrm{CD}$ and $\mathrm{Cl}$ translations were increased with increasing concentrations of NIM811 at $48 \mathrm{~h}$ (Figures 6a-c). Interestingly, the inappropriate acceleration of CD translation at $48 \mathrm{~h}$ occurred most robustly at NIM811 concentrations that corresponded to those that caused cell vacuolization and death (10 and $15 \mu \mathrm{M})$.

We next addressed the question as to whether short treatments with rapamycin, torin-2 or cycloheximide would impact the two branches of protein translation at late time points after NIM811 addition. U251 cells were pretreated for 2 or $4 \mathrm{~h}$ with the inhibitors, and then replaced with NIM811 containing media for 48 additional hours before testing using the dual-luciferase assay. Short treatments with either of the mTOR inhibitors or with cycloheximide restrained the abnormal CD translation induced by NIM811 at $48 \mathrm{~h}$ (Figure 6e). However, cycloheximide was unique in also suppressing $\mathrm{Cl}$ translation, whereas the mTOR inhibitors allowed increased $\mathrm{Cl}$ translation to continue (Figure $6 \mathrm{~d}$ ). Importantly, the ratio of $\mathrm{Cl}$ to $\mathrm{CD}$ translation was significantly enhanced by brief pretreatment with rapamycin; in agreement with its ability to suppress vacuolization in NIM811-treated cells (Figure 6f). However, it was puzzling that cycloheximide treatment also inhibited vacuolization yet did not induce the favorable change in this ratio, thus raising the question of how it could allow survival in the face of NIM811 treatment.

To try to resolve this, we performed RNA-seq on total mRNA from cells pretreated with cycloheximide for $2 \mathrm{~h}$, and then incubated with NIM811 for $20 \mathrm{~h}$. Comparison with NIM811 alone-treated cells, RNA-seq revealed significant downregulations in genes associated with autophagy (ATG8, ULK1 and P62) and UPR (ATF4 and ATF3) by cycloheximide (Supplementary Table 2). In agreement with this, cycloheximide partially suppressed the NIM811-induced conversion of LC3-I to II, and early loss of p62, suggesting that cycloheximide suppressed, rather than enhanced autophagy, unlike 

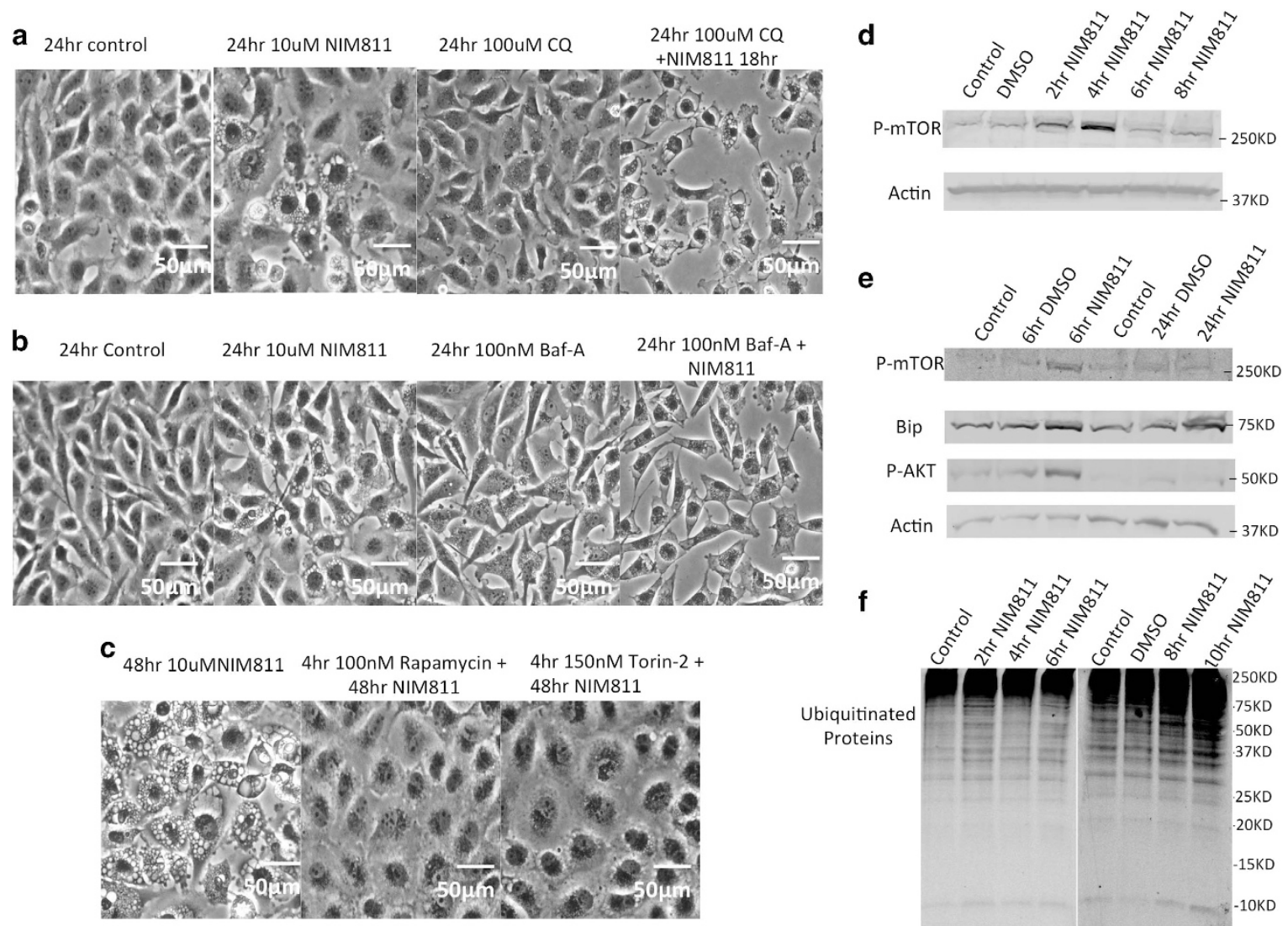
NIM811

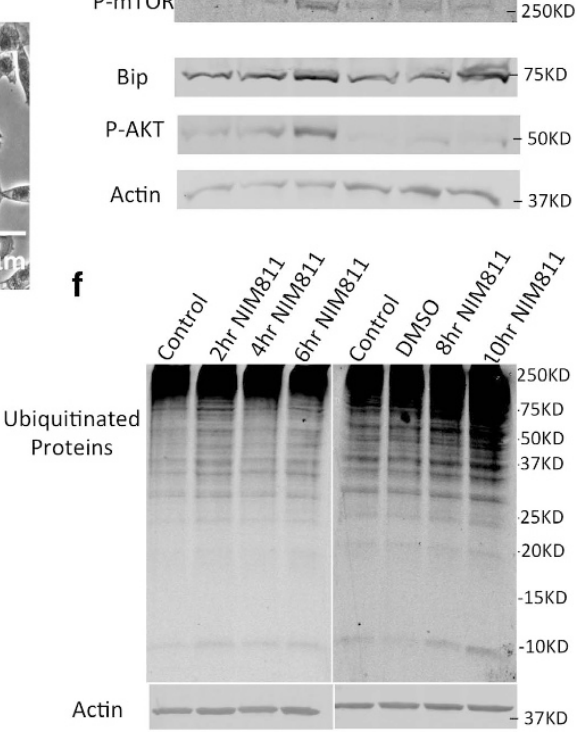

Figure 5 mTOR inhibitors block NIM811-induced vacuolization. (a and $\mathbf{b})$ U251 cells were treated with $10 \mu \mathrm{M}$ NIM811 in combination with $100 \mu \mathrm{M}$ chloroquine (CQ) or $100 \mathrm{nM}$ bafilomycin A1 (Baf-A) for $24 \mathrm{~h}$. Scale bar $=50 \mu \mathrm{m}$. (c) Four-hour pretreatment with $100 \mathrm{nM}$ rapamycin or $150 \mathrm{nM}$ torin-2 blocked vacuolization in U251 cells at $48 \mathrm{~h}$. Scale bar $=50 \mu \mathrm{m}$. (d and e) Western blotting of NIM81-treated cells demonstrated transient stimulation of mTOR as well as AKT phosphorylation at 2-6 h. Bip remained upregulated after $24 \mathrm{~h}$. (f) Cell lysates were collected from $2 \mathrm{~h}$ to $10 \mathrm{~h}$ of $10 \mu \mathrm{M}$ NIM811-treated U251 cells, and analyzed for protein ubiquitination

the mTOR inhibitors (Figures $7 a$ and b). Furthermore, cycloheximide decreased NIM811-induced P-EIF2a levels, but instead activated phosphorylation of the mTOR target P70S6K, which would serve to exacerbate the protein overload coming into the ER (Figure 7c). At $24 \mathrm{~h}$, cycloheximide still enforced the continued strong induction of P70S6K phosphorylation, whereas suppressing LC3 conversion and Bip expression (Figure 7d). These contrasted with effects of rapamycin, which increased $\mathrm{P} 62$ clearance and reduced the levels of P-P70S6K.

Although the ability of cycloheximide to reverse paraptotic vacuolization and cell death has been described multiple times, its effects on the UPR, autophagy, and $\mathrm{Cl}$ to $\mathrm{CD}$ ratio, which differed significantly from those of mTOR inhibitors, raised the question of whether vacuolization should truly be equated with cell death. To reveal this connection between cell death and vacuolization, we compared the cell numbers between NIM811 only treated cells and the ones pretreated with $2 \mathrm{~h}$ cycloheximide. Shockingly, although cycloheximide could efficiently delay vacuole formation, it failed to provide any survival benefit to cells at $24 \mathrm{~h}$ of culture (Figure $8 \mathrm{a}$ ), nor at earlier time points (Supplementary Figure 9). To more accurately assess cell survival, we used colony formation assays. Two hours of treatment with cycloheximide alone had no impact on colony formation. However, brief pretreatment with cycloheximide markedly enhanced the amount of cell death caused by NIM811 (Figures 8b, c and Supplementary Figure 3). Conversely, rapamycin significantly reversed the effects of NIM811 (Figures 8b, c and Supplementary Figure 3). Similar to rapamycin, torin-2 substantially restored the colony numbers and reduced vacuolization within NIM811-treated cells (Supplementary Figures 4A and 4C).

NIM811-induced paraptosis is cyclophilin dependent. To determine whether NIM811 mediates paraptosis depends on its function as cyclophilin inhibitor, we applied shRNA mediated depletion to knockdown two major human cyclophilins: cyclophilin A and B. ${ }^{15}$ Interestingly, a modest degree of spontaneous cytoplasmic vacuolization was initiated after the loss of cyclophilin A or B (Supplementary Figures 7A and $7 \mathrm{~B}$ ), and moreover, the knockdown cells became paraptotic in response to NIM811 treatment at much lower concentrations. All cyclophilin A and B depleted cells formed cytoplasmic vacuoles within $12 \mathrm{~h}$ of $2.5 \mu \mathrm{M}$ NIM811 incubation, which was not observed in control knockdown cells (Supplementary Figure 7C). Thus, we conclude that NIM811 
a

CAP-Independent Translation

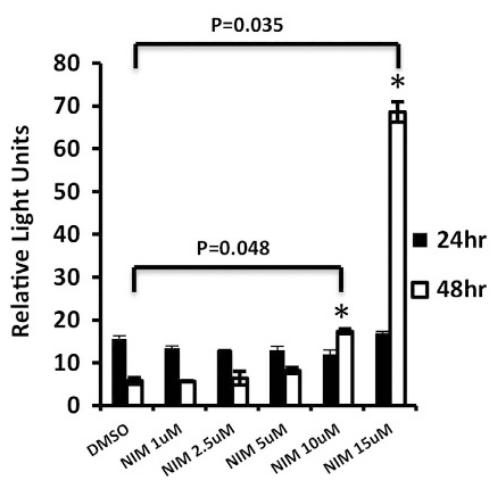

d

CAP-Independent Translation

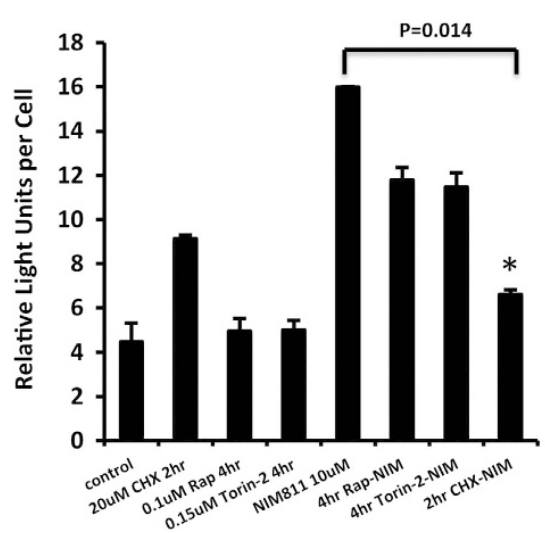

b

CAP-Dependent Translation

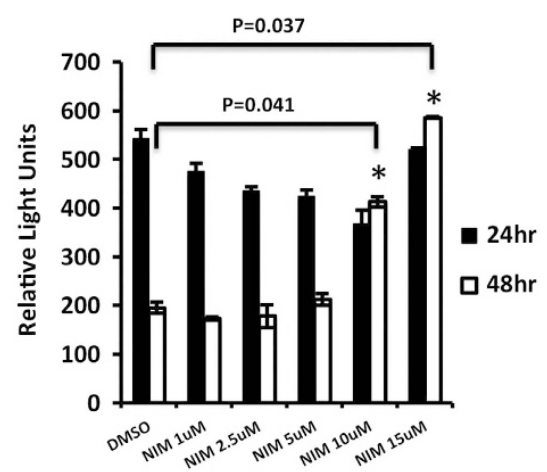

e

CAP-Dependent Translation

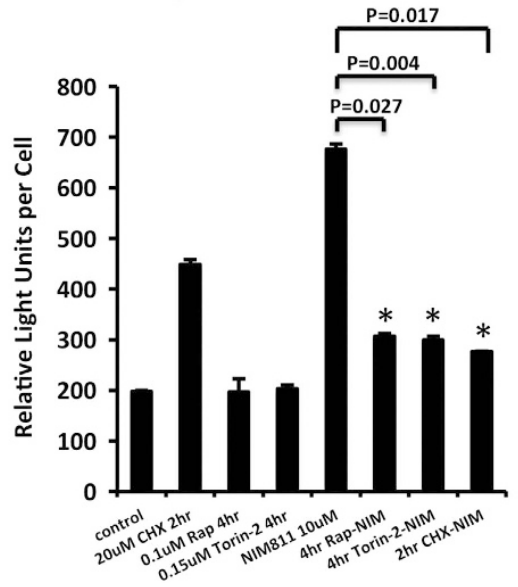

C

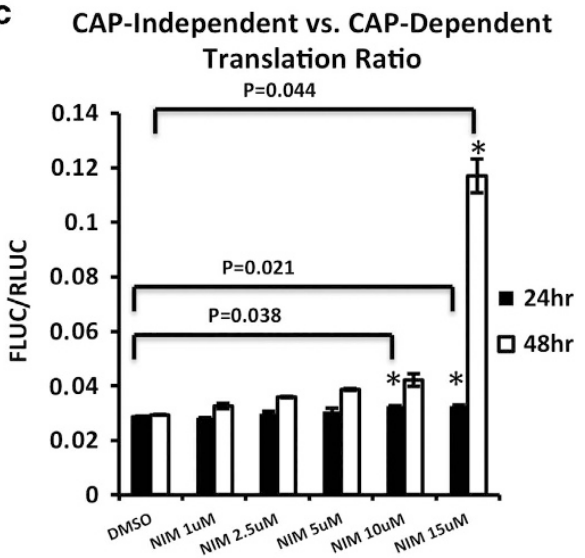

f

CAP-Independent vs. CAPDependent Translation Ratio

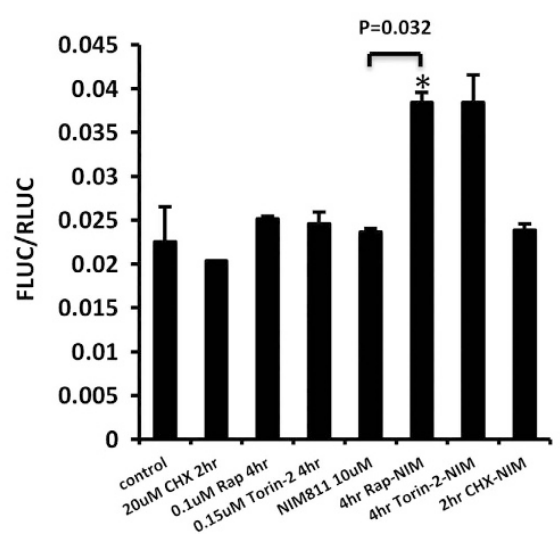

Figure 6 NIM811 activates both $\mathrm{CD}$ and $\mathrm{Cl}$ translation. (a-c) CD and $\mathrm{Cl}$ translation were measured by the dual renilla/firefly luciferase assay after 24 or $48 \mathrm{~h}$ of indicated treatments, and relative light units were normalized to cell numbers. NIM811 significantly increased the $\mathrm{Cl}$ and $\mathrm{CD}$ translation at 10 and $15 \mu \mathrm{M}$, ${ }^{*} P<0.05$. (d-f) Pretreatment of rapamycin, torin-2 effectively decreased CD translation during NIM811 incubation, whereas brief pretreatment with cycloheximide substantially decreased both $\mathrm{CD}$ and $\mathrm{CI}$ translation. ${ }^{*} P<0.05$

induces paraptosis by blocking the anti-paraptotic effects of these cyclophilins.

\section{Discussion}

Here, we have identified NIM811 as a novel inducer of paraptotic cell death in GBM cells, with the signature finding of ballooning cytoplasmic vacuoles that displace the morphologically unchanged nucleus. NIM811-induced vacuoles arose from the ER, and there was evidence for prolonged activation of ER stress. Several findings underlined the importance of the complex time course of signaling events during the early (reversible) and late (irreversible) stages of NIM811-induced cell death. The early response was accompanied by three transient events: induction of the UPR, acceleration of autophagy and mTOR activation. These occurred before the irreversible stage, which began around $10 \mathrm{~h}$, and which featured accumulation of unfolded ubiquitinated proteins, enlargement of cytosolic vacuoles to accommodate them, and ultimately, increased protein synthesis (Supplementary Figures $5 \mathrm{~A}$ and $5 \mathrm{C}$ ). Our favored model is that mTOR activation and increased protein synthesis contributed to the ultimate cell death, whereas transient activation of autophagy and the UPR resisted cell death unsuccessfully.

Although the precise target of NIM811 is not clarified yet, we suspect that its ability to bind and inhibit many of the cellular cyclophilins underlies its activity. In addition to blocking the action of CypB and CypC in the ER, ${ }^{39,40}$ it is also able to bind to the CypD in the mitochondria and the primary cytosolic CypA ${ }^{40,41}$ Depleting cyclophilin A and B accelerated NIM811induced cellular vacuolization, thus further supporting the idea that NIM811 mediates paraptosis in a cyclophilin-dependent manner.

Importantly, NIM811 significantly boosted both CD and CI protein synthesis. The accepted model for relief of ER stress is that $\mathrm{Cl}$ proteins are primarily chaperones or other foldases that assist with the business of processing incoming $C D$ proteins. $^{32,33}$ Thus, the ratio of $\mathrm{Cl}$ to $\mathrm{CD}$ translation should increase in response to a heightened state of ER stress. Although $10 \mu \mathrm{M}$ of NIM811-induced evidence of ER stress, the UPR was aborted, and the ratio of $\mathrm{Cl} / \mathrm{CD}$ did not change from that of untreated cells. However, addition of an mTOR inhibitor 


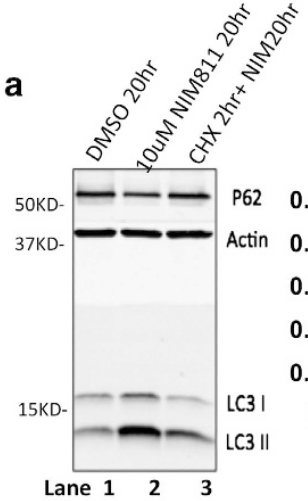

c

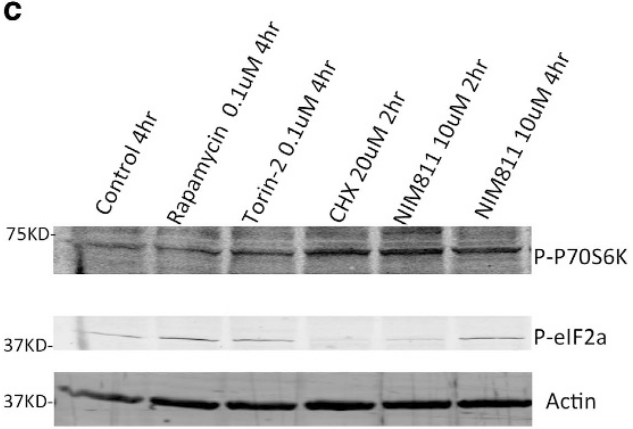

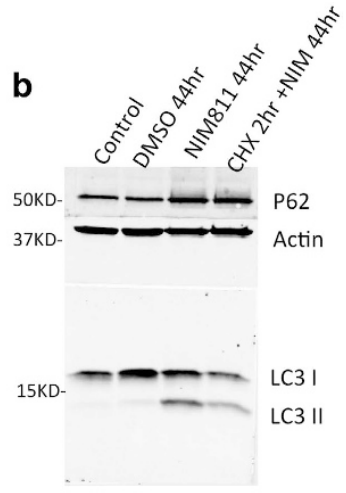

d

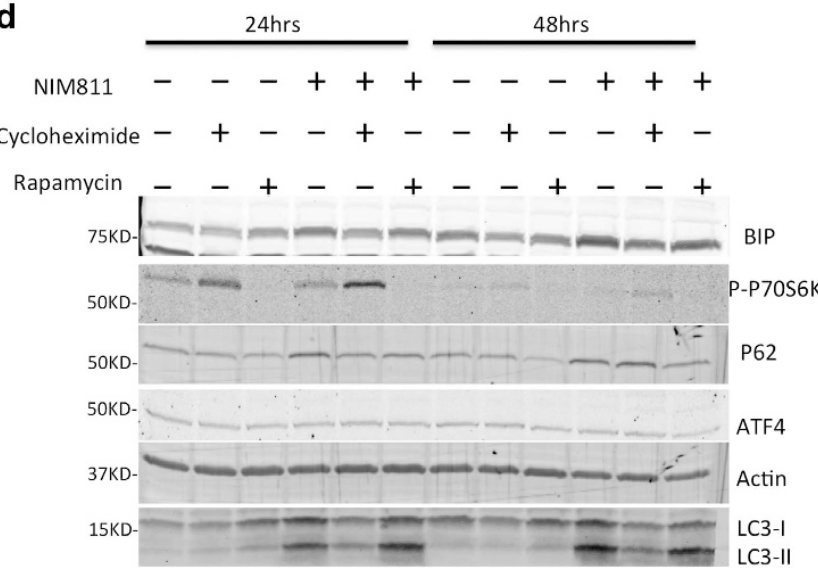

Figure 7 Cycloheximide inhibits autophagy and UPR signaling, whereas activating downstream mTOR substrate phosphorylation. (a) Brief treatment with cycloheximide led to increased p62 accumulation at $20 \mathrm{~h}$ of NIM811 treatment (quantitation with the actin loading control on the right). (b) Two-hour cycloheximide pretreatment decreased LC3-I and II levels even after prolonged NIM811 treatment $(44 \mathrm{~h})$, (c) $10 \mu \mathrm{M}$ NIM811 stimulated phosphorylation of P70S6K at $2 \mathrm{~h}$ and p-EIF2a at $4 \mathrm{~h}$, while $2 \mathrm{~h}$ of cycloheximide increased the P-P70S6K level but decreased elF2a phosphorylation. (d) Two-hour cycloheximide pre-incubation boosted the p-p70S6K level after $24 \mathrm{~h}$, whereas, with rapamycin pretreatment, P70S6K phosphorylation decreased and p62 was degraded more efficiently

appropriately increased the $\mathrm{Cl} / \mathrm{CD}$ ratio and dramatically reversed vacuolization and suppressed cell death.

The effects of the protein synthesis inhibitor cycloheximide on NIM811-induced paraptosis events deserve additional study in the future. On the one hand, its addition completely blocked the development of cytosolic vacuoles, as has been shown for other paraptotic drugs. On the other hand, although others have claimed that cycloheximide also prevents paraptotic death, we found the opposite that it causes enhanced cell death when combined with NIM811. We suspect an important cause of this was its negative impact on both $C D$ and $\mathrm{Cl}$ protein translations as well as autophagy. As a result, the $\mathrm{Cl} / \mathrm{CD}$ ratio did not improve from untreated or NIM811 alone treated cells, and ER stress would not have been effectively resolved. Its suppression on autophagy further sensitized the cells to death. In re-examining published reports of paraptosis, we find that others did not typically perform colony-forming assays or FACS analysis, and instead primarily evaluated cell death within a short time period (1 day or so) of drug treatment. Therefore, it is possible that others missed the additive or synergistic effects of interruption of protein synthesis on paraptotic death in their systems. Thus, we carefully tested cycloheximide pretreatment either in other cell lines followed by NIM811 treatment (Supplementary Figure 9), or with two other paraptosis inducers ophiobolin $\mathrm{A}^{6}$ and celastrol ${ }^{7}$ at both 24 and $72 \mathrm{~h}$. We found that cycloheximide only prevented vacuolization but failed to save cells from death (Supplementary Figure 6). This result further indicates that ER vacuolization may be a protective response generated by cells to isolate defective proteins within the ER in order to prevent those misfolded aggregates to damage the cellular homeostasis. For that reason, simply inhibiting the vacuole formation without clearing the ER protein build-up would not be sufficient to terminate the cell death.

This result also underlines the importance of evaluating cellular responses in non-apoptotic cell death experiments over multiple time frames to judge the true impact. After all, the essential goal is to eradicate malignant cells over the course of weeks to years, rather than over $24 \mathrm{~h}$.

A striking finding from this work is the marked and longlasting impact of a 2-4 h pretreatment of cells with inhibitors of either protein synthesis or mTOR. Particularly in the latter case, rapamycin or torin-2 exposure for as little as $4 \mathrm{~h}$ was sufficient to allow essentially normal cell proliferation up to 2 weeks later. This effect was accompanied by a change in the ER stress response, most clearly demonstrated by the prolonged phosphorylation of elF2a, which is known to increase the $\mathrm{Cl} / \mathrm{CD}$ ratio. We hypothesize that this reveals 
a

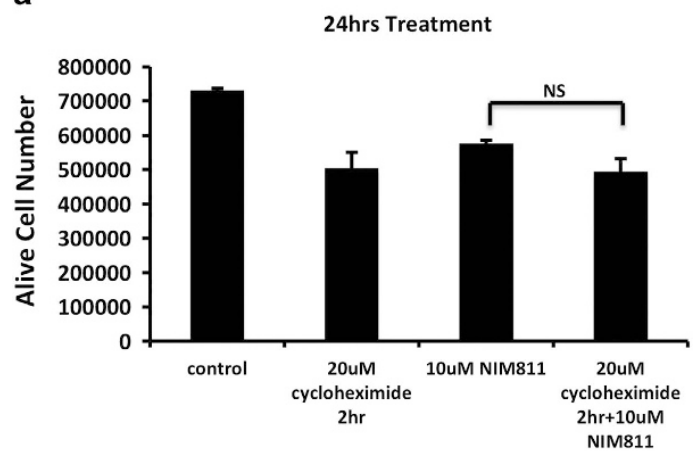

C

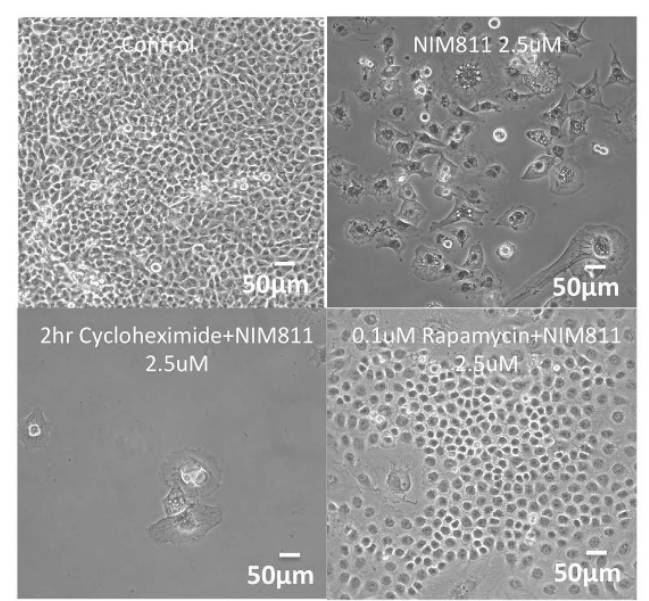

b

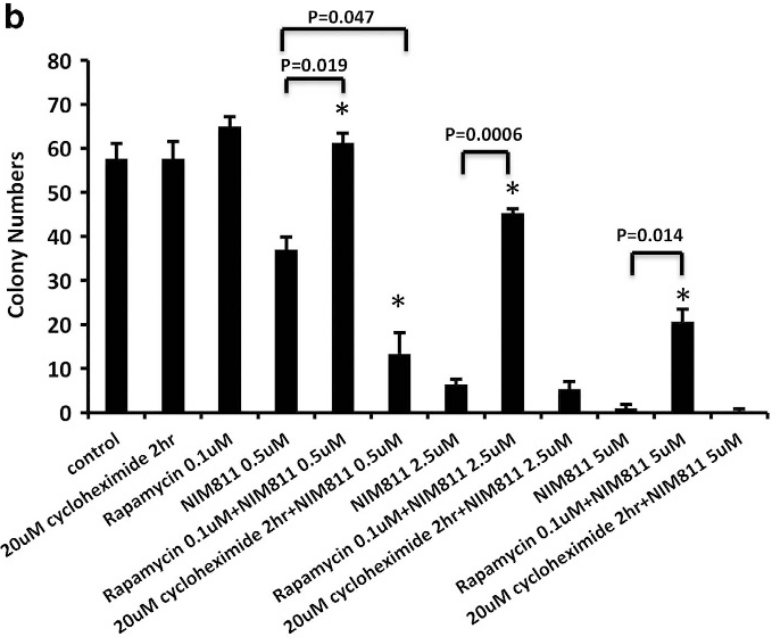

Figure 8 Cycloheximide pretreatment exacerbates cell death induced by prolonged NIM811 treatment. (a) Cycloheximide pretreatment did not improve U251 live cell numbers after $24 \mathrm{~h}$ of $10 \mu \mathrm{M}$ NIM811 incubation. (b) Colony number counts on day 13 indicates that pretreatment with rapamycin significantly increased colony numbers over NIM811 alone treatment (from 0.5 to $5 \mu \mathrm{M}$ ), ${ }^{*} P<0.05$, whereas, cycloheximide pretreatment substantially decreased colony numbers by $0.5 \mu \mathrm{M}$ NIM811 incubation, ${ }^{*} P<0.05$. (c) Microscopic images were obtained on day 13 to demonstrating the morphology of the colony cells. Rapamycin also blocked the vacuolization triggered by NIM811. Scale bar $=50 \mu \mathrm{m}$

the presence of a competitive race, beginning at the onset of drug exposure, between effective inductions of ER stress resistance via the UPR versus stress-induced loss of effective UPR signaling resulting from impaired ER chaperone function. Although still hypothetical, we note that cyclophilin B has been shown to associate in complexes with Bip, CHOP and Grp94, ${ }^{42,43}$ all of which have known roles in mediating the UPR response. Furthermore, we previously showed that knockdown of cyclophilin B could impair certain aspects of the UPR. ${ }^{16}$ As ER stress intensifies, therefore, the functions of the UPR components may become impaired, and so become unable to transmit a 'distress' signal, thus leading to a worsening spiral of stress-induced destruction. On the other hand, a brief delay in the ER stress induced by rapamycin or torin-2, via enhanced autophagy and elevation of the Cl/CD ratio, may be sufficient to allow the UPR to stay ahead of the NIM811-induced stress.

\section{Materials and Methods}

Cell culture and reagents. GBM cell lines (U251 and T98G) were grown in DMEM, 10\% FBS. G22VF cells were generated as previously described, ${ }^{44}$ and were also grown in the same media as U251 cells. Reagents (cycloheximide, blasticidin, Qvd-oph, chloroquine, tunicamycin and thapsigargin) were purchased from Sigma-Aldrich (St. Louis, MO, USA). U0126 and bafilomycin-A1 were purchased from InvivoGen (San Diego, CA, USA). NIM811 was requested from
Novartis (Basel, Switzerland). Rapamycin was from Alfa Aesar (Ward Hill, MA, USA), and torin-2 was obtained from Tocris Bioscience (Bristol, UK).

Plasmid transfection and cellular organelle labeling. pEGFP-LC3 (human) was a gift from Toren Finkel (Plasmid \#24920, Addgene, Cambridge, MA, USA), and pcDNA3 RLUC POLIRES FLUC was a gift from Nahum Sonenberg (Plasmid \#45642, Addgene), ER, mitochondria and lysosome were labeled with cellLight reagents (C10590, C10601 and C10597, Thermo Fisher Scientific, Waltham, MA, USA).

20S proteasome activity assay. Cell lysate triplicates were harvested after indicated treatments. Then, the proteasome activities were measured by BMLAK740 assay kit from Enzo life sciences (Farmingdale, NY, USA).

Western blot. Cell lysates were prepared at indicated time points, and the procedures were described elsewhere. ${ }^{45}$ Antibodies used were the followings: mouse anti-ubiquitin (13-1600, Invitrogen, Camarillo, CA, USA), mouse actin (mab1501, EMD Millipore, Billerica, MA, USA), ATF4 (sc-200, Santa Cruz Biotechnology, Dallas, TX, USA), EIF2a (\#9722, Cell Signaling Technology, Danvers, MA, USA), P-EIF2a (\#9721, Cell Signaling Technology), Bip (ab21685, Abcam, Cambridge, UK), p62 (ab194129, Abcam), LC3B (NB100-2220, Novus Biologicals, Littleton, CO, USA), P-mTOR (\#2971, Cell Signaling Technology), P-AKT (\#9271, Cell Signaling Technology) and P-P70S6K (\#9205, Cell Signaling Technology).

Immunofluorescence staining. U251 cells were plated on glass slides in six-well plate at a concentration of $0.3 \mathrm{E}+06$ cells per well. After $24 \mathrm{~h}$ of DMSO or $10 \mu \mathrm{M}$ NIM811 treatment, cells were first fixed with $4 \%$ formaldehyde (in 1× PBS), and permeabilized with $0.1 \%$ Triton $X-100$. Then cells were incubated in blocking 
solution ( $5 \%$ goat serum in $1 \times$ PBS) for $1 \mathrm{~h}$, and stained by primary antibody P62 (Cell Signalling; \#7695) for $1 \mathrm{~h}$. Finally, cells were labeled with anti-rabbit IgG (Alexa Fluor 647) for $1 \mathrm{~h}$, and Hoechst 33342 (Thermo Fisher Scientific; 62249) was applied at $1 \mu \mathrm{g} / \mathrm{ml}$ for $3 \mathrm{~min}$. Thereafter, cells were imaged under fluorescence microscope.

Dual-Iuciferase assay. On day $0,5 \mu \mathrm{g}$ of pcDNA3 RLUC POLIRES FLUC plasmid was transfected into U251 cells that seeded on $10 \mathrm{~cm}$ dish. On day 1 , cells were splited and seeded $0.3 \mathrm{E}+06$ cells per well onto six-well plates. On day 2, cells were treated with indicated drugs either for 24 or $48 \mathrm{~h}$.

Translations were measured by Dual-Luciferase reporter assay system (E1910, Promega, Madison, WI, USA).

Cell viability, cell death, colony formation assay. Cell viability test was conducted with PrestoBlue (Thermo Fisher Scientific; A13261) according to the manufacturer's instructions. Live cell numbers were assessed through flow cytometry. For colony formation assay, 100 cells were seeded onto each well of six-well plate on day 0 and treated with drugs as indicated, and colony numbers were quantified by staining with coomassie blue after 13 days of treatments.

Xenograft experiment. $2 \mathrm{E}^{6}$ G22VF cells per mice were inoculated to 30 nude mice via subcutaneously injection. When the tumor sizes reached $100 \mathrm{~mm}^{3}$, the mice were randomly divided into three groups to receive corresponding treatments three times per week. NIM811 were prepared by dissolving $50 \mathrm{mg}$ of NIM811 into $10 \mathrm{ml}$ of vehicle $(0.9 \mathrm{ml}$ of cremophor EL+0.1 ml of ethanol $+9 \mathrm{ml}$ of normal saline).

Statistical analysis. Data were analyzed by two-tailed Student's $t$-tests to determine the significance of a difference deviation between two means, and significant difference was represented by ${ }^{*} P<0.05$.

\section{Conflict of Interest}

The authors declare no conflict of interest.

Acknowledgements. We greatly appreciate Norvatis for providing NIM811 for this study, Lonn Lindquist for mouse experiments and the Mayo Gene Expression Core for gene expression analysis. We are grateful to all members of Bram's Lab for invaluable discussions. This work was supported by the NIH Grant R01-NS77555.

1. Thurnher MM. 2007 World Health Organization classification of tumours of the central nervous system. Cancer Imag Off Publ Int Cancer Imag Soc 2009; 9(Spec No): S1-S3.

2. Ellor SV, Pagano-Young TA, Avgeropoulos NG. Glioblastoma: background, standard treatment paradigms, and supportive care considerations. J Law Med Ethics 2014; 42: 171-182.

3. Mao H, Lebrun DG, Yang J, Zhu VF, Li M. Deregulated signaling pathways in glioblastoma multiforme: molecular mechanisms and therapeutic targets. Cancer Invest 2012; 30: 48-56.

4. Sperandio S, de Belle I, Bredesen DE. An alternative, nonapoptotic form of programmed cell death. Proc Natl Acad Sci USA 2000; 97: 14376-14381.

5. Lee D, Kim IY, Saha S, Choi KS. Paraptosis in the anti-cancer arsenal of natural products. Pharmacol Ther 2016; 162: 120-133.

6. Bury M, Girault A, Mégalizzi V, Spiegl-Kreinecker S, Mathieu V, Berger W et al. Ophiobolin A induces paraptosis-like cell death in human glioblastoma cells by decreasing BKCa channel activity. Cell Death Dis 2013; 4: e561.

7. Wang WB, Feng LX, Yue QX, Wu WY, Guan SH, Jiang BH et al. Paraptosis accompanied by autophagy and apoptosis was induced by celastrol, a natural compound with influence on proteasome, ER stress and Hsp90. J Cell Physiol 2012; 227: 2196-2206.

8. Lang K, Schmid FX, Fischer G. Catalysis of protein folding by prolyl isomerase. Nature 1987; 329: 268-270.

9. Yao Q, Li M, Yang H, Chai H, Fisher W, Chen C. Roles of cyclophilins in cancers and other organ systems World J Surg 2005; 29: 276-280.

10. Davis TL, Walker JR, Campagna-Slater V, Finerty PJ, Paramanathan R, Bernstein G et al. Structural and biochemical characterization of the human cyclophilin family of peptidyl-prolyl isomerases. PLoS Biol 2010; 8: e1000439.

11. Canafax DM, Ascher NL. Cyclosporine immunosuppression. Clin Pharm 1983: 2: $515-524$.

12. Wiederrecht G, Lam E, Hung S, Martin M, Sigal N. The mechanism of action of FK-506 and cyclosporin A. Ann N Y Acad Sci 1993; 696: 9-19.

13. Billich A, Hammerschmid F, Peichl P, Wenger R, Zenke G, Quesniaux V et al. Mode of action of SDZ NIM 811, a nonimmunosuppressive cyclosporin A analog with activity against human immunodeficiency virus (HIV) type 1: interference with HIV protein-cyclophilin A interactions. $J$ Virol 1995; 69: 2451-2461.

14. Ma S, Boerner JE, TiongYip C, Weidmann B, Ryder NS, Cooreman MP et al. NIM811, a cyclophilin inhibitor, exhibits potent in vitro activity against hepatitis $C$ virus alone or in combination with alpha interferon. Antimicrob Agents Chemother 2006; 50: 2976-2982.

15. Lee J, Kim S. Current implications of cyclophilins in human cancers. J Exp Clin Cancer Res 2010; $29: 97$.

16. Choi JW, Schroeder MA, Sarkaria JN, Bram RJ. Cyclophilin B supports MYC and mutant p53-dependent survival of glioblastoma multiforme cells. Cancer Res 2014; 74: 484-496.

17. Vermes I, Haanen C, Steffens-Nakken H, Reutelingsperger C. A novel assay for apoptosis. Flow cytometric detection of phosphatidylserine expression on early apoptotic cells using fluorescein labelled Annexin V. J Immunol Methods 1995; 184: 39-51.

18. Van Engeland M, Ramaekers FCS, Schutte B, Reutelingsperger CPM. A novel assay to measure loss of plasma membrane asymmetry during apoptosis of adherent cells in culture. Cytometry 1996; 24: 131-139.

19. Caserta TM, Smith AN, Gultice AD, Reedy MA, Brown TL. Q-VD-OPh, a broad spectrum caspase inhibitor with potent antiapoptotic properties. Apoptosis 2003; 8: 345-352.

20. Degterev A, Huang Z, Boyce M, Li Y, Jagtap P, Mizushima $N$ et al. Chemical inhibitor of nonapoptotic cell death with therapeutic potential for ischemic brain injury. Nat Chem Biol 2005; 1: 112-119.

21. Huang C, Luo Y, Zhao J, Yang F, Zhao H, Fan W et al. Shikonin kills glioma cells through necroptosis mediated by RIP-1. PLOS ONE 2013; 8: e66326.

22. Svidritskiy E, Ling $C$, Ermolenko DN, Korostelev Aa. Blasticidin $S$ inhibits translation by trapping deformed tRNA on the ribosome. Proc Natl Acad Sci USA 2013; 110: 12283-12288.

23. Yoon MJ, Kang YJ, Lee JA, Kim IY, Kim MA, Lee YS et al. Stronger proteasomal inhibition and higher CHOP induction are responsible for more effective induction of paraptosis by dimethoxycurcumin than curcumin. Cell Death Dis 2014; 5: e1112.

24. Rock KL, Gramm C, Rothstein L, Clark K, Stein R, Dick L et al. Inhibitors of the proteasome block the degradation of most cell proteins and the generation of peptides presented on MHC class I molecules. Cell 1994; 78: 761-771.

25. Lee IH, Cao L, Mostoslavsky R, Lombard DB, Liu J, Bruns NE et al. A role for the NAD-dependent deacetylase Sirt1 in the regulation of autophagy. Proc Natl Acad Sci USA 2008; 105: 3374-3379.

26. Gonzalez-Noriega A, Grubb JH, Talkad V, Sly WS. Chloroquine inhibits lysosomal enzyme pinocytosis and enhances lysosomal enzyme secretion by impairing receptor recycling. J Cell Biol 1980; 85: 839-852.

27. Yamamoto A, Tagawa Y, Yoshimori T, Moriyama Y, Masaki R, Tashiro Y. Bafilomycin A1 prevents maturation of autophagic vacuoles by inhibiting fusion between autophagosomes and lysosomes in rat hepatoma cell line, H-4-II-E cells. Cell Struct Funct 1998; 23: 33-42.

28. Sabers CJ, Martin MM, Brunn GJ, Williams JM, Dumont FJ, Wiederrecht G et al. Isolation of a protein target of the FKBP12-rapamycin complex in mammalian cells. J Biol Chem 1995; 270: 815-822.

29. Liu Q, Wang J, Kang SA, Thoreen CC, Hur W, Ahmed T et al. Discovery of 9-(6aminopyridin-3-yl)-1-(3-(trifluoromethyl)phenyl)benzo[h][1,6]naphthyridin-2(1H)-one (Torin2) as a potent, selective, and orally available mammalian target of rapamycin (mTOR) inhibitor for treatment of cancer. J Med Chem 2011; 54: 1473-1480.

30. Wang X, Proud CG. The mTOR pathway in the control of protein synthesis. Physiology (Bethesda) 2006; 21: 362-369.

31. Pelletier J, Sonenberg N. Internal initiation of translation of eukaryotic mRNA directed by a sequence derived from poliovirus RNA. Nature 1988; 334: 320-325.

32. Hellen CUT, Sarnow P. Internal ribosome entry sites in eukaryotic mRNA molecules. Genes Dev 2001; 15: 1593-1612.

33. Liu B, Qian SB. Translational reprogramming in cellular stress response. Wiley Interdisciplinary Rev RNA 2014; 5: 301-305.

34. Harding HP, Zhang $Y$, Bertolotti A, Zeng $H$, Ron D. Perk is essential for translational regulation and cell survival during the unfolded protein response. Mol Cell 2000; 5: 897-904.

35. Harding HP, Novoa I, Zhang Y, Zeng H, Wek R, Schapira M et al. Regulated translation initiation controls stress-induced gene expression in mammalian cells. Mol Cell 2000; 6: 1099-1108.

36. Ron $D$, Walter $P$. Signal integration in the endoplasmic reticulum unfolded protein response. Nat Rev Mol Cell Biol 2007; 8: 519-529.

37. Sarnow P. Translation of glucose-regulated protein $78 /$ immunoglobulin heavy-chain binding protein mRNA is increased in poliovirus-infected cells at a time when cap-dependent translation of cellular mRNAs is inhibited. Proc Natl Acad Sci USA 1989; 86 : 5795-5799.

38. Poulin F, Gingras AC, Olsen H, Chevalier S, Sonenberg N. 4E-BP3, a new member of the eukaryotic initiation factor $4 \mathrm{E}-$ binding protein family. J Biol Chem 1998; 273 : 14002-14007.

39. Watashi K, Ishii N, Hijikata M, Inoue D, Murata T, Miyanari $Y$ et al. Cyclophilin B is a functional regulator of hepatitis C virus RNA polymerase. Mol Cell 2005; 19: 111-122.

40. Gaither LA, Borawski J, Anderson LJ, Balabanis KA, Devay P, Joberty G et al. Multiple cyclophilins involved in different cellular pathways mediate HCV replication. Virology 2010; 397: 43-55. 
41. Waldmeier PC, Feldtrauer J-J, Qian T, Lemasters JJ. Inhibition of the mitochondrial permeability transition by the nonimmunosuppressive cyclosporin derivative NIM811. Mol Pharmacol 2002; 62: 22-29.

42. Kim J, Choi TG, Ding Y, Kim Y, Ha KS, Lee KH et al. Overexpressed cyclophilin B suppresses apoptosis associated with ROS and $\mathrm{Ca} 2+$ homeostasis after ER stress. J Cell Sci 2008; 121: 3636-3648.

43. Jeong K, Kim H, Kim K, Kim S. Cyclophilin B is involved in p300-mediated degradation of CHOP in tumor cell adaptation to hypoxia. Cell Death 2013; 21: 438-450.

44. Carlson BL, Pokorny JL, Schroeder MA, Sarkaria JN. Establishment, maintenance and in vitro and in vivo applications of primary human glioblastoma multiforme (GBM) xenograft models for translational biology studies and drug discovery. Curr Protoc Pharmacol 2011; 52: $1-14$.

45. Choi JW, Sutor SL, Lindquist L, Evans GL, Madden BJ, Bergen HR 3rd et al. Severe osteogenesis imperfecta in cyclophilin B-deficient mice. PLoS Genet 2009; 5: e1000750. (c) (i) Cell Death and Disease is an open-access journal published by Nature Publishing Group. This work is licensed under a Creative Commons Attribution 4.0 International License. The images or other third party material in this article are included in the article's Creative Commons license, unless indicated otherwise in the credit line; if the material is not included under the Creative Commons license, users will need to obtain permission from the license holder to reproduce the material. To view a copy of this license, visit http://creativecommons.org/licenses/by/4.0/

(C) The Author(s) 2017

Supplementary Information accompanies this paper on Cell Death and Disease website (http://www.nature.com/cddis) 